\title{
Value of transvaginal ultrasonography versus Bishop Score in predicting successful induction of labor
}

\section{Prospective Comparative Study}

\author{
Marwa Eid ${ }^{1}$, Amal Kotb Abdallah ${ }^{2}$ and Ahmed ElHalwagy ${ }^{1}$ \\ ${ }^{\prime}$ Department of Obstetrics and Gynaecology, Faculty of Medicine, Cairo University \\ ${ }^{2}$ Department of Obstetrics and Gynecology, Faculty of Medicine, Beni-suef \\ University, Egypt
}

\begin{abstract}
Background: Induction of labor is a widely used intervention in modern labor. Bishop score, the gold standard for assessing favourability for induction of labor is very subjective with a poor predictive value.

Objective: To compare the transvaginal ultrasonography and the score proposed by Kepansereel in prediction of success of labor induction.

Patients and Methods: A prospective study involved 50 women subjected to induction of labor. Preinduction assessment of Bishop score and ultrasound measurement of cervical length, posterior cervical angle and cervical funnelling was done. Results: 35 and 15 cases had successful and unsuccessful induction.Cervical length was significantly longer and posterior cervical angle was significantly larger in cases of failed induction $(p<0.001$ for both). The Bishop score and Keepanasseril core were significantly lower in association with induction failure ( $p<0.001$ for both).

Conclusion: Successful induction correlated significantly with the Bishop score and ultrasonographic cervical length and posterior cervical angle.
\end{abstract}

Key Words: Bishop Score, induction of labour, new objective scoring system, ultras-sonographic evaluation of the cervix

Received: 12 June 2017, Accepted: 16 August 2017

Corresponding Author: Amal Kotb Abdallah, Obstetrics \& Gynecology Department, Beni-Suef University, Beni-Suef, Egypt, Tel.: 01065059597, E-mail: amalkotb7295@yahoo.com

ISSN: 2090-7265, November 2017, Vol.7, No. 4

\section{INTRODUCTION}

Induction of labour is always indicated when the benefits to the mother and the fetus exceeds those of continuing the pregnancy as in cases of past-date, IUGR or in some medical disorders of pregnancy ${ }^{[1]}$

Some cervical characteristics or "Ripening" of the cervix have been related to the successful induction of labour. ${ }^{[2]}$

Bishop Score is considered as the gold standard in the prediction of the duration and outcome of induced labour. However, the favourability of the cervix as assessed by the Bishop score is very subjective and has been demonstrated by several studies as a poor predictive value for the outcome on induction of labour especially in women with a low Bishop score. ${ }^{[3]}$

The sonographic assessment of the cervical length and the occipital position has been shown to be superior to the Bishop score in the prediction of outcome of labour in women undergoing induction. ${ }^{[4,5]}$
Using pre-induction sonographic parameters and maternal characteristics to predict the outcome of induction might lead to reduction in caesarean delivery and its complications. ${ }^{[6]}$

Transvaginal ultra-sonographic measurements could represent a more accurate assessment of the cervix than digital examinations as the supravaginal portion represent about $50 \%$ of the cervical length and cannot be assessed digitally. In addition, effacement is subjective and can vary considerably among examiners and is difficult to determine in the closed cervix ${ }^{[7]}$. In contrast, transvaginal ultrasonographic cervical measurement is quantitative and easily reproducible ${ }^{[8]}$.

In women undergoing induction of labour, preinduction sonographic assessment of cervical length and occipital position was found to be superior to the Bishop score in the prediction of outcome of labour ${ }^{[4,5]}$.

The aim of this study is to determine whether the Ultrasonography measurements of the cervical length, posterior cervical angel and cervical funnelling are good 
predictors for successful induction of labor and to validate the predictability of new objective scoring systems for the cervical favourability.

\section{PATIENTS AND METHODS}

This prospective comparative study was conducted at the casualty department of Kasr El Aini Hospital in the period from November 2016 to March 2017. Induction if labor was done using prostaglandin E1 for cases with unfavorable cervices with a bishop score $5-7$ and by oxytocin infusion for favorable cervices with bishop score $>7$.

The study was approved by kasr AlAiny local Ethics Committee and informed written consent was obtained from all participants

Women included in this study were those with singleton living fetuses, cephalic presentations, with gestational age more than 37 weeks, with intact membranes and with bishop score of the cervix $>5$.

Exclusion criteria were Women with multifetal pregnancies, Women diagnosed with malpresentations, IUFD ,Any degree of placenta previa and/or vasaprevia, Women diagnosed with a major degree of cephalopelvic disproportion by standard clinical tests, Any non reassuring CTG ,Women with active genital herpes or invasive cervical cancer which contraindicate vaginal delivery, Extreme low birth weight defined as $<1500 \mathrm{~g}$,Previous operations on the cervix (e.g. cautery, cerclage, cervical amputation or conization), Patients with previous myomectomy or cesarean section ,Patients already in active labor on admission .

Ultrasound was done using (Voluson 58-GE ultrasound Korea.1td.9.Sunhwan-ro-214beon-gil, Gyneonggi-do, Korea) machine equipped with a 4-7 MHz transabdominal probe with the woman in supine, slightly tilted to left lateral side to avoid supine hypotension to confirm the GA (originally determined by the use of sure dates and early 1 st trimester ultrasound examination), fetal viability, weight, wellbeing and to ensure adherence to inclusion and exclusion criteria. The women were asked to empty the bladder then evaluation with $3.5-5 \mathrm{MHz}$ transvaginal probe by the same examiner. Fundal or suprapubic pressure was not exerted. Ultrasound measurements were made in the sagittal plane. Measurements taken for cervical length, cervical funneling and posterior cervical angle were taken. Cervical length was determined by the simultaneous visualization of the external and internal cervical os and their measurement across the endocervical channel. Funneling was defined as a protrusion of the amniotic membranes $3 \mathrm{~mm}$ or more into the internal os. Posterior cervical angle is measured in a sagittal plane at the level of the internal os, as the angle between an imaginary line traversing the cervical canal and another tangential to the posterior uterine wall at its junction with the internal os. Values will be approximated to the nearest degree. In case of a funneled or an excessively curved cervix, the angle will be assessed at the junction of the line measuring the cervical length and the posterior uterine wall. Parameters of the Bishop's scoring system (the fetal station and the consistency, position, dilation and effacement of the cervix) were done by vaginal examination and Bishop score was calculated.

Labor induction was done according to standard guidelines for induction of labor by:1.Prostaglandin E1, (misoprostol) for unfavorable cervices with a Bishop score $<7$,Initial dose 25 microgram vaginal tablet then Full reassessment 6 hours after initial dose then a Second dose 25 micrograms in cases with unfavorable cervix. Reassessment every 6 hours later and re-dosing if cervix was still unfavorable. If no cervical ripening after 4 doses of misoprostol, the procedure was considered a failure and the patient was delivered by Caesarean section. If there is cervical ripening we moved to the next step.

2.Oxytocin and/or Amniotomy: Oxytocin started by 5 units in $500 \mathrm{ml}$ of normal saline or "Ringer's solution" 6 hours following the last dose of misoprostol starting with a rate of 12 drops/minute. Infusion rate was increased (by doubling drops/minute) at intervals of 30 minutes, until there are 3 good contractions in 10 minutes, each lasting 4560- seconds. Maximum allowed rate was 84 drops/ minute

During the period of induction, the fetal heart rate was monitored continuously, by means of external electronic fetal heart rate monitoring (Cardiotocography),Also maternal monitoring was done including blood pressure measurements every 2 hours and frequent clinical evaluation (according to the condition).

The primary outcome was induction success (defined as the ability to achieve the active phase of labor ; cervical dilation more than or equal to 4 centimeter)

The secondary outcomes were induction to delivery interval (IDI) and Apgar score of the newborn at 1 and 5 minutes. Using the definition of Watson et al (1996), an induction attempt was considered successful if the patient reached the active phase of labor as demonstrated by progressive dilatation and effacement of the cervix and followed by vaginal delivery. All women's data were recorded in a special input form.

Scoring system used for assessment of inducibility ${ }^{[9]}$. The score ranges from 0 to 13 . With the best cut-off point for the prediction of successful induction of labour was 6 for the new score. The new score of 6 had a 
Table 1: Kepansereel Scoring system used for assessment of inducibility (9)

\begin{tabular}{|c|c|c|c|c|c|}
\hline Parameter & 0 & 1 & 2 & 4 & 8 \\
\hline Parity & Nullipara & Multipara & & & \\
\hline Cervical length & More than $3.2 \mathrm{~cm}$ & & & $2.1-3.2 \mathrm{~cm}$ & Less than $2.1 \mathrm{~cm}$ \\
\hline $\begin{array}{l}\text { Posterior } \\
\text { cervical angle }\end{array}$ & Less than 90 degrees & & $90-100$ & $\begin{array}{c}\text { More than } 110 \\
\text { degrees }\end{array}$ & \\
\hline
\end{tabular}

\section{STATISTICAL ANALYSIS}

Data were statistically described in terms of mean \pm standard deviation ( \pm SD), or frequencies (number of cases) and percentages when appropriate. Comparison of numerical variables between the study groups was done using Student $t$ test for independent samples. For comparing categorical data, Chi square $(\chi 2)$ test was performed. Exact test was used instead when the expected frequency is less than 5 . P values less than 0.05 was considered statistically significant. All statistical calculations were done using computer programs SPSS (Statistical Package for the Social Science; SPSS Inc., Chicago, IL, USA) version 15 for Microsoft Windows.

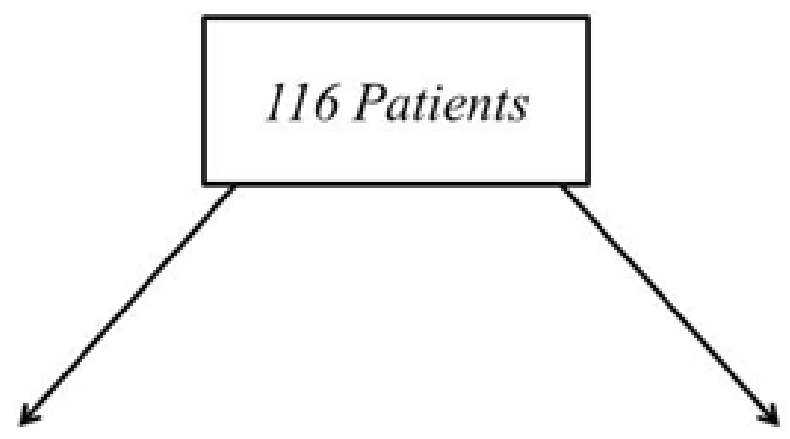

Fits to our inclusion criteria

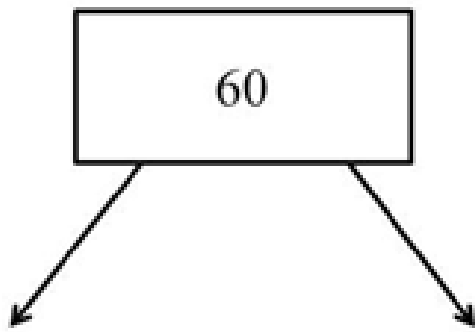

Excluded

56

Continued Study

Drop Outs 


\section{RESULTS}

The age of the studied group $(n=50)$ ranged between 17 and 41 years with a mean of $24.3 \pm 5.7$. They were 20 primigravidas and 30 multiparas. The BMI ranged between 22 and $38 \mathrm{~kg} / \mathrm{m} 2$ with a mean of $26.0 \pm 4.2$ $\mathrm{kg} / \mathrm{m} 2$. The mean gestational age was $38.9 \pm 2.0$ weeks (range: 35-42 weeks). The indication for induction of labor was passed date in 19 women (38\%), rupture of membranes in $18(36 \%)$, pregnancy induced hypertension in $11(22 \%)$ and gestational diabetes in $2(4 \%)$.

There was no significant difference between women with successful induction and those with failed induction regarding age, parity, BMI, gestational age or indications for induction of labor (table 2).

Table 2: Clinical characteristics and outcome of induction

\begin{tabular}{|c|c|c|c|}
\hline & Induction & Induction & $\mathrm{p}$ value \\
\hline & $\begin{array}{l}\text { Success } \\
(\mathrm{n}=35)\end{array}$ & $\begin{array}{l}\text { failure } \\
(\mathrm{n}=15)\end{array}$ & \\
\hline Age (years) & $23 \pm 4.9$ & $27.2 \pm 6.6$ & 0.438 \\
\hline $\begin{array}{l}\text { Parity } \\
\text { Primigravida }(n=20) \\
\text { Multipara }(n=30)\end{array}$ & $\begin{array}{c}12(60 \%) \\
23(88.2 \%)\end{array}$ & $\begin{array}{c}8(40 \%) \\
7(21.8 \%)\end{array}$ & 0.156 \\
\hline $\begin{array}{l}\text { Height } \\
\text { Body mass index }(\mathrm{kg} / \mathrm{m} 2) \\
\text { Gestational age (weeks) } \\
\text { Indication } \\
\text { GA }>42 \text { weeks }\end{array}$ & $\begin{array}{c}164.8 \pm 9.9 \\
29.2 \pm 3.8 \\
38.8 \pm 1.9 \\
13(68.4 \%)\end{array}$ & $\begin{array}{l}163.3 \pm 9.6 \\
29.3 \pm 5.8 \\
39.0 \pm 2.2 \\
6(31.6 \%)\end{array}$ & $\begin{array}{l}0.633 \\
0.921 \\
0.776\end{array}$ \\
\hline $\begin{array}{l}\text { ROM } \\
\text { PIH } \\
\text { Gestational Diabetes } \\
\text { Neonatal birth Weight }(\mathrm{gm})\end{array}$ & $\begin{array}{c}14(77.0 \%) \\
8(72.7 \%) \\
0(0.0 \%) \\
3221 \pm 394\end{array}$ & $\begin{array}{c}4(23.0 \%) \\
3(27.3 \%) \\
2(100.0 \%) \\
3616 \pm 632\end{array}$ & $\begin{array}{l}0.202 \\
0.010\end{array}$ \\
\hline
\end{tabular}

There was a significantly higher neonatal birth weight among those with failed induction when compared to women with successful induction (table 2)

Induction succeeded in 35 women (70\%); 15 women were delivered by caesarean section. The indication of caesarean section was failed induction (no cervical dilatation and effacement after 4 doses of misoprostol with 6-hour intervals), failure of progress, fetal distress or placental abruption. As shown in table 3, success of induction was not significantly associated with age $(p=0.438)$, parity $(p=0.156)$, gestational age $(p=0.776)$,
BMI $(p=0.921)$ and indication of induction $(p=0.202)$. Failed induction was significantly associated with higher birth weight $(p=0.010)$.

Cervical length was significantly longer and posterior cervical angle was significantly larger in cases of failed induction ( $p<0.001$ for both). The Bishop score and Kepansereel score were significantly lower in association with induction failure $(p<0.001$ for both). There was no significant association between the percentage of funnelling and failure of induction $(\mathrm{p}=0.163)($ table 3$)$.

Table 3: Bishop score and ultrasonographic criteria in relation to induction outcome

\begin{tabular}{lccc}
\hline & $\begin{array}{c}\text { Induction Success } \\
(\mathrm{n}=35)\end{array}$ & $\begin{array}{c}\text { Induction failure } \\
(\mathrm{n}=1 \mathrm{p} 5)\end{array}$ & $\mathrm{p}$ value \\
\hline Bishop score & $4.4 \pm 1.3$ & $3.2 \pm 1.1$ & $<0.001$ \\
Kepansereel Score & $6.4 \pm 3.3$ & $3.9 \pm 3.1$ & $<0.001$ \\
Cervical length (mm) & $27 \pm 6 \mathrm{~mm}$ & $35 \pm 6$ & $<0.001$ \\
Posterior Cervical Angel $\left({ }^{\circ}\right)$ & $99.2 \pm 13.9$ & $94.2 \pm 8.0$ & $<0.001$ \\
Percentage of Funnelling $(\%)$ & $8.3 \pm 10.0$ & $4.0 \pm 7.6$ & 0.163 \\
\hline
\end{tabular}

At a cut-off of Bishop Score of 5 the sensitivity was $56.0 \%$, specificity was $98.4 \%$, positive predictive value (PPV) was $86.7 \%$ and negative predictive value (NPV) was $47.11 \%$ in prediction of successful induction. These values were $61.2 \%, 91.3 \%, 88.6 \%$, and $59.4 \%$, respectively using a Keepanasseril score at a cut-off of 6 (Table 4) 
Table 4: Accuracy of Bishop Score Vs Kepansereel score in prediction of successful induction

\begin{tabular}{lccccc}
\hline & Cut off & Sensitivity & Specificity & PPV & NPV \\
\hline Bishop & 5 & $56 \%$ & $98.4 \%$ & $86.7 \%$ & 47.11 \\
Kepansereel & 6 & 61.2 & 91.3 & 88.6 & 59.4 \\
\hline
\end{tabular}

\section{DISCUSSION}

Induction of labour is a common practice in modern obstetrics. Increasing the need to predict the outcome of labor induction in women with unfavourable. Transvaginal ultrasonography has always been a method to predict preterm deliveries, and recently it is used successfully to predict the outcome of labour induction with varying success. Bishop's scoring system is the commonest method to determine the success of labour induction although it is very subjective and several studies have demonstrated a poor predictive value for the outcome of induction especially in women with a low Bishop score ${ }^{[3]}$

Transvaginal ultrasound measurement of cervical length is a more objective method for cervical assessment ${ }^{[10,11,12]}$

In our study $(70 \%)$ of our 50 participants were delivered vaginally and $(30 \%)$ women were delivered by C.S.

The present study found that successful induction of labour correlated significantly with the Bishop score $(p<0.001)$, The posterior cervical angle $\quad(p<0.001)$, ultrasonographic cervical length $(p<0.001)$ and Keepanasseril score $(p<0.001)$. we found a statistically significant positive correlation between cervical length and posterior cervical angle measured by ultrasound and failure of induction and probability of C.S. and a statistically significant negative correlation between both scores ( Bishop and Keepanasseril ) and failure of induction and probability of C.S.

This agree with Yang et al. ,they also found that successful induction correlated significantly with the Bishop Score and cervical length ${ }^{[13]}$.

Also in contrast to Groeneveld et al., with our results as they chose a longer interval (96h) between start of induction and vaginal delivery in order to avoid caesarean delivery as much as possible. Their caesarean delivery rate was $17.3 \%$ compared with $30 \%$ in our study. But that long period may be considered extra burden on the participants comparing with our interval $48 \mathrm{~h}$ as prolonged trial of labour leads to maternal exhaustion and longer hospitalization with consequent increased morbidity and financial cost. ${ }^{[2]}$.

Bastani et al. agreed with our results as they found cervical length measured by transvaginal ultrasonography has the potential to replace the traditional Bishop score ${ }^{[14]}$.

Rane et al., also agreed with us as they found that cervical length and parity are good predictors of success of vaginal delivery within 24 hours of induction ${ }^{[15]}$

Tan et al. in their study performed on 249 women admitted for labor induction, found that analysis of the ROC curves for cervical length and Bishop Score indicated that both were predictors of Cesarean delivery .Moreover they found that Transvaginal sonography was significantly less painful than digital examination for Bishop Score assessment ${ }^{[6]}$.

Limitations of our study was that our cohort of patients was limited to patients whose gestational age $>42$ weeks, PIH, ROM and those with gestational diabetes and we excluded other patients who might have higher rates for successful induction.

The value of our work that it can provide us with information regarding successful induction through simple techniques ( vaginal examination and ultrasonography)

\section{CONCLUSION}

We found that successful induction correlated significantly with the Bishop score and ultrasonographic cervical length and posterior cervical angle. We suggest that a better prediction of the outcome of labour can be achieved by Keepanasseril Score which is a more objective scoring.

\section{CONFLICT OF INTEREST}

There is no conflict of interest.

\section{REFERENCES}

1. Anish K, Vanita S, Rashmi B et al. Pre-induction sonographic assessment of the cervix in the 
prediction of successful induction of labor in nulliparous women. Australian and New Zealand Journal of Obstetrics and Gynaecology 2007; 47: 389-393.

2. Groenevelda Y, Bohnenb A, Van heusdenc A: Cervical length measured by transvaginal ultrasonography versus Bishop score to predict successful labour induction in pregnancies. F, V \& V In OBGyn, 2010, 2 (3): 187- 193.

3. Selhi M, Surapaneni T: Pre induction sonographic measurement of cervical length : An adjunct to Bishop Score?, Fernandez Hospital Journal of Perinatalogy, 2010,Issue 1, Article.

4. Rane SM, Guirgis RR, Higgins B, Nicolaides $\mathrm{KH}$ : The value of ultrasound in the prediction of successful induction of labor ultrasound obstet Gynecol 2004; 24: 538 -549.

5. Keepanasseril A, Suri V, Bagga R, Aggarwal N.Preinduction sonographic assessment of the cervix in the prediction of successful induction of labor in nulliparous women;2007, 47 (5):389- 93.

6. Tan PC., Vallikkannu N., Suguna S., Quek K. F. and Hassan J.: Transvaginal sonographic measurement of cervical length vs. Bishop score in labor induction at term: tolerability and prediction of Cesarean delivery, Ultrasound Obstet Gynecol 2007; 29: 568-573

7. Zilanri M, Azuaga A, Calderon F, Pages G, Mendoza G: Monitoring the effacement of the uterine cervix by transperineal Sonography: Anew prespective. J Ultrasound: Med 14:719- 24, 1995

8. Ware V, Raynor BD: Trans-vaginal ultrasonographic cervical measurement as a predictor of successful labour induction. Am J Obstet Gynecol 2000; 182: 1030 -1032.
9. Keepanasseril A, SuriV,Bagga, Aggarwal N.A new objective scoring system for the prediction if successful induction of labour. $\mathrm{J}$ obstet Gynaecol.2012;32(2):145- 7.

10. Rozenberg P. Transvaginal Ultrasound of the Cervix: hope in the Fight against Premature delivery. J Radiol. 1999;80: 421 -9 .

11. Pandis GK, Papageorghiou AT, Ramanathan Mo, Thompson Om, Nicolaides KH. Preinduction sonographic measurement of cervical length in the prediction of successful induction of labour. Ultrasound obstet Gynecol 2001; 1: 623 -8.

12. Roman H, Verspyck E, Vercoustre 1., Degre S, Col JY, Firmin Jm, : Does ultrasound examination when the cervix is unfavorable improve the prediction of failed labor induction? Ultrasound Obstet Gynecol 2004: 23: 357 -62.

13. Yang SH, Cheong RR, Jong HK: Trans-vaginal ultrasonography for cervical length assessment before induction of labour. J Ultrasound Med 2004; 23: 375- 382 .

14. Bastani Parvin, Kobra Hamdi, Fatemeh Abadalizadeh, Parisa Pourmousa and Fatemeh Ghatrehsamani: Transvaginal ultrasonography compared with Bishop Score for predicting cesarean section after induction of labour. Int. J. Women's Health, 3: 3: 277- 280, 2011.

15. Rane S.M., Pandis G.K., Guirgis R.R., Higgins B. and Nicolaides K.H.: Pre-induction sonographic measurement of cervical length in prolonged pregnancy the effect of parity in the prediction of the need for Caesarean section. Ultrasound Obstet. Gynecol., 22: 45- 8, 2003 .. 